\title{
Survival of Rickettsia conorii in artificially contaminated whole and leukoreduced canine blood units during the storage period
}

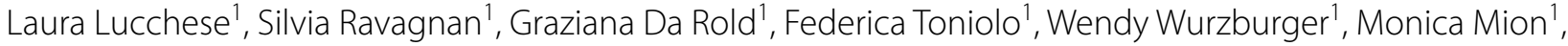
Antonio Carminato ${ }^{1}$, Pierre-Edouard Fournier ${ }^{2}$, Gioia Capelli ${ }^{*}$, Alda Natale ${ }^{1}$ and Marta Vascellari ${ }^{1}$

\begin{abstract}
Background: The ability of tick-borne agents to survive in stored blood bags is a key factor for their transmissibility by blood transfusion. The aim of this study was to evaluate the survival and potential infectivity of Rickettsia conorii $(\mathrm{RC})$ in artificially contaminated canine whole blood (WB) and in leukoreduced whole blood (LR-WB) during the storage period.

Methods: RC was cultured on L929 cells. We used a one-week $25-\mathrm{cm}^{2}$ flask with $70-80 \%$ of L929 infected cells to prepare the bacterial inoculum by pelleting cells and suspending the pellet in the donors'serum. We infected five 100 $\mathrm{ml} \mathrm{WB}$ units with $\mathrm{RC}$ within $2 \mathrm{~h}$ from the collection and maintained it at room temperature for $4 \mathrm{~h}$ prior to refrigeration. We filtered $50 \mathrm{ml}$ of each WB bag to obtain leukoreduced WB (LR-WB) at day 1 post-infection (dpi). We checked WB and LR-WB bags at 1, 4, 7, 14, 21, 28, 35 dpi for RC presence and viability through real-time PCR (rPCR) for DNA and mRNA, respectively, and by isolation. Identification of isolates was confirmed by indirect immunofluorescence and rPCRs.
\end{abstract}

Results: RC survived for the entire storage period in both whole and leukoreduced blood. All bags contained viable bacteria until $7 \mathrm{dpi}$; RC viability generally decreased over time, particularly in LR-WB bags where the isolation time was longer than in WB. Viable bacteria were still isolated at 35 dpi in 3 WB and 3 LR-WB.

Conclusions: Leukoreduction reduced but did not eliminate $R C$ in infected units. The survival and infectivity of $R C$ in canine blood during the storage period may represent a threat for recipients.

Keywords: Leukoreduction, Blood transfusion, Rickettsia conorii, Dog

\section{Background}

Transfusion medicine has acquired increasing importance in veterinary practice during the last decades and the establishment of blood banks, particularly for dogs, has led to a wider availability and use of blood components in life-saving therapy as well as the need of adequate screening tests for donors to minimize the risk of pathogen transmission by transfusion.

\footnotetext{
*Correspondence: gcapelli@izsvenezie.it

${ }^{1}$ Istituto Zooprofilattico Sperimentale delle Venezie, Legnaro, PD, Italy

Full list of author information is available at the end of the article
}

Among infectious agents, those transmitted by ticks are critical threats in transfusion medicine because of their transmissibility by blood. Ehrlichia spp., Babesia spp. and Anaplasma spp. are typically included in recommended testing for canine donors, but other pathogens may be assessed on the basis of geographical distribution and clinical significance [1]. Several Rickettsia spp. belonging to the spotted fever group are present in southern Europe and are transmitted by tick bites [2]. In particular, Rickettsia conorii (RC), the causative agent of Mediterranean spotted fever in 
humans, is transmitted by the brown dog tick, Rhipicephalus sanguineus, its main vector and possible reservoir in Europe [3]. This species has been shown to be experimentally transmitted to dogs by ticks [4]. Due to the presence of clinical symptoms of illness observed in experimentally infected dogs $[4,5]$, as well as the occurrence of sporadic cases of natural infection [6, 7], it is recommended to include this pathogen in the screening panel for canine blood donors.

The intracellular location of $\mathrm{RC}$, together with the non-specific and sometimes subclinical course of the disease, represent a key factor to assume the RC potential transfusion risk, even though no data regarding the survival and infectivity of RC during the blood storage period is available.

In human medicine, several tick-borne pathogens with intracellular location have raised concerns because of the risks they pose to blood safety [8]. Anaplasma phagocytophilum [9] and Babesia microti [10] have shown to be capable of surviving 18-21 days in stored blood conditions. Furthermore, it is reported that they caused transfusion cases in humans even later than the survival demonstrated in laboratory experiments, suggesting a possible longer transmissibility by infected units [11]. Despite the relevance of this issue, information on survival of many pathogens is still undefined and often based on the age of the blood that transmitted the infection [8]. Rickettsia rickettsii has been suspected to survive at least 9 days in stored blood, because the only transfusion case described acquired the infection from a 9-day refrigerated whole blood unit [12].

Leukoreduction is a common practice in human transfusion medicine, thanks to the use of in-line filters integrated in the bag system, which allow the reduction of the white blood cell count by $99.9 \%$ [13]. The primary effect of leukoreduction is to limit storage lesions, due to leukocyte degradation during storage; a secondary effect could be to remove white blood cells potentially infected by intracellular infectious agents, such as rickettsiae, which can be transmitted to the recipient by the blood transfusion. Leukoreduction seemed to reduce the risk of transfusion-transmitted infections in laboratory models using Orientia tsutsugamushi [14] and Anaplasma phagocytophilum [15], even though pathogens were not completely eliminated from blood units.

Even if leukoreduction is suggested to reduce the risk of transmission of different blood pathogens, the efficacy in eliminating $\mathrm{RC}$ in infected units and the effect on $\mathrm{RC}$ viability under storage conditions are still undetermined.

The aim of this study was to evaluate the survival and the potential infectivity of $\mathrm{RC}$ in canine whole blood (WB) and in leukoreduced whole blood (LR-WB) during a 35-day storage period.

\section{Methods}

\section{Whole blood unit collection}

Canine donors were selected among healthy, privatelyowned dogs included in the blood donor programme of the IZSVe canine blood bank. The donors fulfilled the following inclusion criteria: age 2-8 years; body weight $\geq 25$ $\mathrm{kg}$; clinically healthy; regularly vaccinated and protected against endo- and ectoparasites, according to the Italian Ministry of Health guidelines [16]. At each donation, donors underwent general hematological and biochemical screening, as well as serological and biomolecular tests against vector-borne pathogens (Leishmania spp., Rickettsia spp., Ehrlichia canis, Anaplasma phagocytophilum and Babesia canis). For ethical reasons and considering the clinical importance of the blood unit supply, no more than five registered donors were included in the study. The dogs' owners formally approved the use of part of the donation for research purposes before the sampling and they approved an information form. The donation was performed by a double bag collection system, equipped with an in-line integrated leukocyte reduction filter from the jugular vein after trichotomy and accurate disinfection of the site. The collection bag contained 14 $\mathrm{ml}$ of citrate phosphate-dextrose-adenine (CPDA-1) to collect $100 \mathrm{ml}$ of WB (ratio1:7). The bag system was also equipped with a self-cleaning valve that allowed the collection of blood samples while maintaining the sterility during the study period.

WB units were inoculated within $2 \mathrm{~h}$ from collection, keeping the bags at room temperature to preserve leukocyte viability. Before infection, $1.5 \mathrm{ml}$ of WB were collected from each unit to guarantee the negativity of the WB unit for RC (rPCRs and blood culture on L929 as described below).

\section{$\mathrm{RC}$ culture and blood unit infection}

$\mathrm{RC}$ was cultured at $32{ }^{\circ} \mathrm{C}$ in $5 \% \mathrm{CO}_{2}$ and $95 \%$ humidity on L929 cells, a murine fibroblastic cell line suitable for RC isolation and maintenance $[17,18]$, with MEM enriched with $4 \%$ bovine fetal serum and $1 \%$ of L-glutamine. L929 cells cultured for one-week in a $25-\mathrm{cm}^{2}$ flask until confluent monolayer were infected with $\mathrm{RC}$ and the strain was propagated every week in new $25-\mathrm{cm}^{2}$ flasks using serial inoculum dilutions until infection stabilization to obtain a $25-\mathrm{cm}^{2}$ flask with a monolayer containing $70-80 \%$ of infected cells every week. The cell infection rate was estimated by Gimenez staining on a sample of cells collected from the monolayer and stained on a glass slide. The RC dilution for the inoculum was set according to the limit of detection (LOD) of the real-time PCR assay targeting DNA of RC (assay described below), in order to obtain a WB bag infection rate at the LOD level (10 DNA copies / $\mu \mathrm{l})$. This was achieved using the entire RC production of 
a 1 -week $25-\mathrm{cm}^{2}$ flask to infect $100 \mathrm{ml}$ of WB. The inoculum was prepared after mechanical detachment and partial needle $(27 \mathrm{G})$ separation by pelleting cells (centrifugation at $10000 \times g$ for $10 \mathrm{~min}$ ), removal of the supernatant followed by two washes of the pellet with sterile PBS and by re-suspending the pellet in $1.2 \mathrm{ml}$ of donor's serum, obtaining $1 \mathrm{ml}$ for unit infection and $200 \mu \mathrm{l}$ for molecular analyses. One drop $(c .10 \mu \mathrm{l})$ was examined by Gimenez staining.

WB units were infected with the RC inoculum through the self-cleaning valve using a sterile syringe; the bags were gently shaken to favor the distribution of the infected cells and free RC and kept at room temperature for $2-4 \mathrm{~h}$ to allow infection stabilization. Then, all units were stored at $4{ }^{\circ} \mathrm{C} \pm 2$, simulating ordinary storage conditions. At day 1 post-infection (dpi), half of the WB was filtered for leukoreduction and collected in the secondary bag (LR-WB). Both the WB and LR-WB units were stored at $4{ }^{\circ} \mathrm{C} \pm 2$ for 35 days (unit shelf life).

\section{Infection assessment}

At 1, 4, 7, 14, 21, 28 and $35 \mathrm{dpi}, 1.2 \mathrm{ml}$ of blood were sampled from all WB and LR-WB units and tested through rPCRs for DNA and RNA $(200 \mu \mathrm{l})$ and by culture $(1 \mathrm{ml})$ (Fig. 1) to assess RC presence and viability.

\section{Molecular analyses}

Total DNA and RNA were extracted from $200 \mu \mathrm{l}$ of blood or culture supernatant, using an automated extractor and the MagMax DNA/RNA pathogen kit, according to the manufacturer's instructions (Thermo Fisher Scientific, Waltham, MA, USA). Real-time PCR (rPCR) was used to test RC DNA presence, while RT (reverse transcriptase) rPCR for mRNA was used as a viability marker of the bacterium on rPCR-positive samples.

DNA was amplified using a SYBR green real-time PCR assay performed with the primers RompB OF $\left(5^{\prime}\right.$-GTA ACC GGA ART AAT CGT TTC GT-3') and RompB OR (5'-GCT TTA TAA CCA GCT AAA CCR CC-3'), targeting $511 \mathrm{bp}$ of the $o m p B$ gene [19]. The reaction mix contained $10 \mu \mathrm{l}$ of QuantiFast SYBR green PCR master mix (Qiagen, Hilden, Germany) $(1 \times), 0.2 \mu \mathrm{l}$ of forward and reverse primers $(0.1 \mu \mathrm{M}), 3 \mu \mathrm{l}$ of DNA and RNasefree $\mathrm{H}_{2} \mathrm{O}$ up to a final volume of $20 \mu \mathrm{l}$. The thermal profile consisted of $95^{\circ} \mathrm{C}$ for $5 \mathrm{~min}$, followed by 40 cycles at $95{ }^{\circ} \mathrm{C}$ for $15 \mathrm{~s}, 58^{\circ} \mathrm{C}$ for $30 \mathrm{~s}$ and $60^{\circ} \mathrm{C}$ for $30 \mathrm{~s}$. Following amplification, melt curve analysis was performed by slowly raising the temperature of the thermal chamber from $60{ }^{\circ} \mathrm{C}$ to $95{ }^{\circ} \mathrm{C}$ to distinguish between specific and non-specific amplification products.

A RT real-time PCR assay was applied to mRNA, using the primers Rick-mRNA groEL F (5'-TCC ATA CCG CCC ATA CCT CCC A-3'), and Rick-mRNA groEL R (5'-AGA TGC TGC TTC CGT TGC TTC G-3') and the Rick-mRNA groEL P probe (5'-CCG CCA CGC ATT GGC ATT GGC TCT GCC-3'), targeting 119 bp of the groEL gene [20]. The reaction mix contained $10 \mu \mathrm{l}$ of RTrPCR master mix (Qiagen, Hilden, Germany) $(1 \times), 0.6 \mu \mathrm{l}$ of forward and reverse primers $(0.3 \mu \mathrm{M}), 0.2 \mu \mathrm{l}$ of enzyme mix, $3 \mu \mathrm{l}$ of mRNA and RNase-free $\mathrm{H}_{2} \mathrm{O}$ up to a final volume of $20 \mu \mathrm{l}$. The thermal profile consisted of $20 \mathrm{~min}$ at $50{ }^{\circ} \mathrm{C}, 15$ min at $95^{\circ} \mathrm{C}$, followed by 45 cycles at $94{ }^{\circ} \mathrm{C}$ for $30 \mathrm{~s}$ and $60^{\circ} \mathrm{C}$ for $1 \mathrm{~min}$.

For each DNA and mRNA amplification reactions, a negative $\left(\mathrm{H}_{2} \mathrm{O}\right)$ and positive (Rickettsia spp.) controls were included.

All ompB rPCR products were sequenced, using a 16-capillary ABI PRISM 3130xl Genetic Analyzer (Applied Biosystems, Foster City, CA, USA), to confirm the positivity for RC. Sequence data were assembled and edited with SeqScape software v2.5 (Applied Biosystems). Sequences obtained were aligned and compared with representative sequences available on GenBank.

\section{Blood culture}

Isolation of RC from infected WBs and LR-WBs was performed using the shell-vial technique [21] and L929 cells. For each bag, five shell vial tubes containing a $1 \mathrm{~cm}$ round slide with a confluent L929 cell monolayer and $1 \mathrm{ml}$ of culture medium were inoculated with $200 \mu \mathrm{l}$ of blood. After $1 \mathrm{~h}$ of centrifugation at a low speed $(700 \times$ $g$ ) to favor cell infection, the culture medium containing blood was discarded and replaced with $1 \mathrm{ml}$ of fresh medium. Tubes were incubated at $32{ }^{\circ} \mathrm{C}, 5 \% \mathrm{CO}_{2}$ and

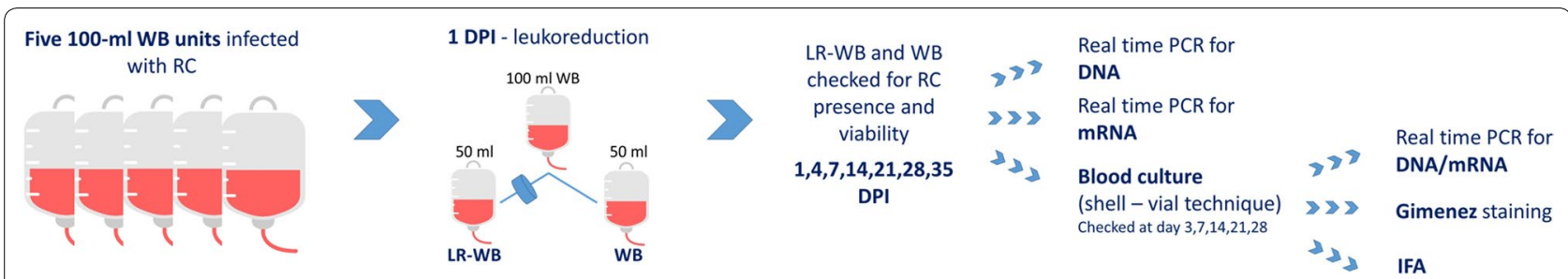

Fig. 1 Graphical representation of the procedure used in this study. Abbreviations:WB, whole blood; LR-WB, leukoreduced whole blood; dpi, day post-infection; RC, Rickettsia conorii 
95\% humidity. Bacterial growth was assessed after 3, 7, 14,21 and 28 days by processing one of the tubes, while the remaining tubes were kept for the following culture monitoring, changing culture medium once a week until day 28 or RC isolation. At every follow-up examination, after collecting a small portion of the infected cell monolayer, the culture supernatant was removed, one drop was put on a slide, dried and stained with the Gimenez method; $200 \mu \mathrm{l}$ of supernatant was tested by rPCR as described for WB and LR-WB samples. The slide with the L929 cell monolayer was fixed with methanol and tested by IFA for the presence of RC as follows: the slide was transferred in a $1 \mathrm{~cm}$ round well with $300 \mu \mathrm{l}$ of RC positive dog serum diluted 1:64 and incubated for $30 \mathrm{~min}$ at $37^{\circ} \mathrm{C}$ in a humid chamber. After two washes with sterile PBS, $300 \mu \mathrm{l}$ of anti-dog fluorescein-labeled antibody (Sigma-Aldrich, St Louis, Missouri, USA) was added and the slide incubated for $30 \mathrm{~min}$ at $37^{\circ} \mathrm{C}$ in a humid chamber, washed twice with PBS and read using a fluorescence microscope. Each negative control tube containing an uninfected L929 monolayer was maintained and tested in the same conditions as the RC culture tubes.

\section{Viability criteria}

$\mathrm{RC}$ viability in blood samples was considered confirmed when $\mathrm{rPCR}$ for mRNA and/or culture gave a positive result. The blood culture test was considered positive when RC was identified by RT-rPCR from infected cells and/or IFA. The identification of intracellular RC by Gimenez staining without positivity to other tests was not considered indicative of RC isolation. The positivity of rPCR-DNA only from both blood and culture supernatant was considered indicative of RC presence, but not viability.

\section{Statistical analysis}

The analysis of variance (ANOVA) was used to compare the average time (in days) of the first positive culture from samples of WB and LR-WB, recorded through the study at each dpi. The agreement among the test used in culture to assess viability of RC in the stored blood units (i.e. rPCR, Gimenez stain and IF) was evaluated using the kappa $(k)$ coefficient. The value of $k$ varies from 0 (perfect discordance) to 1 (perfect concordance) and its interpretation was given as follows: weak (0.1-0.2); moderate $(0.20-0.4)$; discrete $(0.4-0.6)$; substantial $(0.6-0.8)$; and very good concordance $(0.8-1.0)$ [22]. The software used for statistical analysis was SPSS for Windows, version 13.0.

\section{Results}

All rPCR tests and WB culture from the five blood units before infection gave negative results. The $\mathrm{RC}$ inoculum was rPCR-positive in all cases before infection and Gimenez staining of $R C$ culture showed the expected rate of infection. Detailed results of the tests performed in the blood units and on the supernatant samples from the cultures at every dpi are reported in Additional file 1: Table S1.

At $1 \mathrm{dpi}$, all five WB units were RT-rPCR-positive for viable RC, and 2/5 LR-WB units were rPCR-positive only, with no detection of mRNA (Table 1). However, cultures from all five LR-WBs at $1 \mathrm{dpi}$ became positive two weeks later (day 14), showing that a certain amount of viable RC successfully passed through the filter (Table 2). Viable RCs were detectable in all five WB units until $21 \mathrm{dpi}$ and in all five LR-WB units until $7 \mathrm{dpi}$; three units of both WB and LR-WB had viable RC until 35 dpi. LR-WB required a higher mean number of days to obtain a positive culture compared to WB (Fig. 2) (ANOVA: $F_{(32,28)}=5.911$, $P=0.018)$, until $21 \mathrm{dpi}$, suggesting a lower burden in LR-WB units.

Table 1 Results of rPCR-DNA and of RT-rPCR performed on the samples from the blood units at different days post-infection (dpi), in whole blood units (WB) and leukoreduced blood units (LR-WB)

\begin{tabular}{|c|c|c|c|c|c|c|c|c|c|c|}
\hline \multirow{2}{*}{$\begin{array}{l}\text { PCR blood } \\
\text { (dpi) }\end{array}$} & \multicolumn{5}{|c|}{ WB units } & \multicolumn{5}{|c|}{ LR-WB units } \\
\hline & A & B & $C$ & D & $\mathrm{E}$ & A & B & C & D & $E$ \\
\hline 1 & $\mathrm{POS} / \mathrm{V}$ & $\mathrm{POS} / \mathrm{V}$ & $\mathrm{POS} / \mathrm{V}$ & $\mathrm{POS} / \mathrm{V}$ & $\mathrm{POS} / \mathrm{V}$ & $\mathrm{POS} / \mathrm{nv}$ & neg & neg & neg & POS/nv \\
\hline 4 & $\mathrm{POS} / \mathrm{V}$ & neg & $\mathrm{POS} / \mathrm{nv}$ & POS $^{a}$ & neg & $\mathrm{POS} / \mathrm{nv}$ & neg & $\mathrm{POS} / \mathrm{nV}$ & neg & $\mathrm{POS} / \mathrm{nv}$ \\
\hline 7 & $\mathrm{POS} / \mathrm{V}$ & $\mathrm{POS}^{\mathrm{a}}$ & neg & $\mathrm{POS} / \mathrm{V}$ & POS/V & $\mathrm{POS} / \mathrm{nv}$ & neg & neg & neg & neg \\
\hline 14 & $\mathrm{POS} / \mathrm{V}$ & neg & $\mathrm{POS} / \mathrm{nv}$ & POS/V & neg & POS/nv & neg & neg & neg & neg \\
\hline 21 & $\mathrm{POS} / \mathrm{V}$ & neg & neg & neg & $\mathrm{POS} / \mathrm{V}$ & neg & neg & neg & neg & POS/nv \\
\hline 28 & $\mathrm{POS} / \mathrm{V}$ & $\mathrm{POS} / \mathrm{nv}$ & $\mathrm{POS} / \mathrm{nv}$ & $\mathrm{POS} / \mathrm{V}$ & neg & $\mathrm{POS} / \mathrm{nv}$ & neg & neg & neg & neg \\
\hline 35 & $\mathrm{POS} / \mathrm{V}$ & neg & neg & neg & $\mathrm{POS} / \mathrm{V}$ & $\mathrm{POS} / \mathrm{nV}$ & neg & neg & neg & $\mathrm{POS} / \mathrm{V}$ \\
\hline
\end{tabular}

a Not tested by RT-rPCR

Abbreviations: v, viable bacteria; $n v$, non-viable bacteria; $\mathrm{POS} / \mathrm{nv}$, positive $\mathrm{rPCR}$ only; $\mathrm{POS} / \mathrm{v}$, positive RT-rPCR 
Table 2 Day $(3,7,14,21$ and 28) of the culture positivity from samples taken at each day post-infection in whole blood (WB) and leukoreduced blood (LR-WB) units

\begin{tabular}{|c|c|c|c|c|c|c|c|c|c|c|}
\hline \multirow{3}{*}{$\begin{array}{l}\text { Day post- } \\
\text { infection }\end{array}$} & \multicolumn{10}{|c|}{ Day of isolation } \\
\hline & \multicolumn{2}{|c|}{ Unit A } & \multicolumn{2}{|c|}{ Unit B } & \multicolumn{2}{|c|}{ Unit C } & \multicolumn{2}{|c|}{ Unit D } & \multicolumn{2}{|c|}{ Unit E } \\
\hline & WB & LRWB & WB & LRWB & WB & LRWB & WB & LRWB & WB & LRWB \\
\hline 1 & 7 & 14 & 7 & 14 & 3 & 14 & 7 & 14 & 7 & 14 \\
\hline 4 & 3 & 3 & 3 & 14 & 3 & 3 & 7 & 28 & 3 & 3 \\
\hline 7 & 3 & 14 & 14 & 14 & 3 & 7 & 21 & 28 & 7 & 14 \\
\hline 14 & 14 & neg & 14 & 14 & 3 & 14 & 14 & neg & 14 & 21 \\
\hline 21 & 14 & 21 & 14 & 14 & 3 & 7 & 7 & neg & 7 & 14 \\
\hline 28 & 21 & 3 & 7 & 7 & 3 & neg & neg & neg & 14 & 14 \\
\hline 35 & 28 & 14 & 14 & neg & ne & 14 & ne & neg & 3 & 14 \\
\hline
\end{tabular}

Abbreviations: ne, not examined; neg, negative

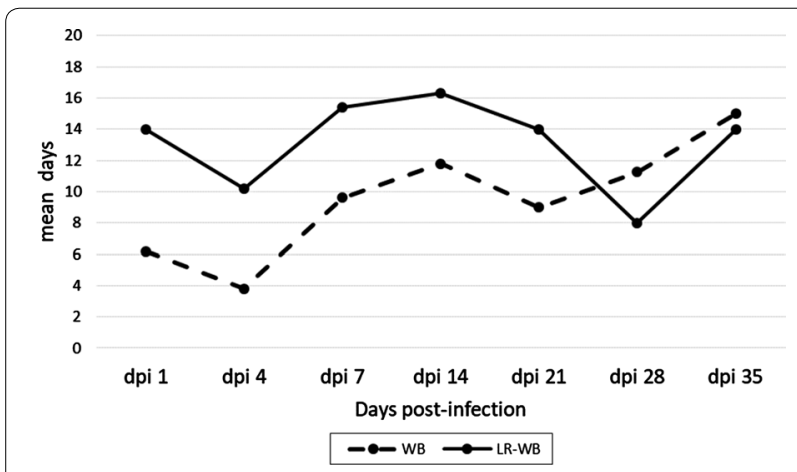

Fig. 2 Mean number of days required to obtain positivity for RC on culture from blood collected at days post-infection (dpi) 1, 4, 7, 14, 21, 28 and 35 in whole blood units (WB) and leukoreduced blood units (LR-WB)

Considering the combined results of the tests performed on blood and cultures, all WB and LR-WB blood units were classified positive, either by RT-rPCR from blood and/or evidence of growth in culture.

Tests on blood culture showed a substantial agreement in identifying RC, with a few exceptions: in 3 cases, IFA tested positive before rPCRs; and in 7 cases, mRNA was detected before IFA was positive (Additional file 1: Table S1). In more detail, the $k$ coefficient (measure of concordance) was 0.698 between rPCR and IFA, 0.626 between rPCR and Gimenez stain and 0.761 between Gimenez stain and IFA.

For two blood cultures, the Gimenez staining allowed detecting the presence of intracellular RC before IFA or rPCRs. In only one case, the detection of RC by Gimenez staining in a LR-WB at 4 dpi was not confirmed by any other test. Neither evidence of aspecific L929 cytopathic effect nor bacterial/yeast culture contamination was registered by microscopic cell observation during the experiment and negative control tubes always tested negative.

\section{Discussion}

This study highlighted that leukoreduction reduced but did not eliminate RC in infected units. RC could still remain viable at $4{ }^{\circ} \mathrm{C}$ during the storage period when $\mathrm{RC}$ passed the blood filter, even if no evidence of $\mathrm{RC}$ replication was obtained.

No previous data are available regarding the survival and possible replication of $\mathrm{RC}$ in stored blood units. Since $\mathrm{RC}$ is an obligate intracellular bacterium, it was not expected to survive during the entire storage period. Unexpectedly, this study demonstrated that RC was able to remain viable in WB stored until 35 days. Moreover, we demonstrated that, despite leukoreduction can eliminate almost all circulating cells that could support RC survival, LR-WB maintained a potential RC infectivity during the entire storage period.

Coxiella burnetii, another obligate intracellular gramnegative bacterium, was demonstrated to survive free in stored blood units and blood products until $45 \mathrm{dpi}$ [23], but the environmental stability and the capacity of C. burnetii to form a spore-like variant [24] are not described for RC. Long-term survival was also reported for A. phagocytophilum, with a viability in blood observed until day 18 at $4{ }^{\circ} \mathrm{C}$ [9]. In addition, viable bacteria were detected after leukoreduction in blood units experimentally spiked with infected cells [15]. However, the duration of A. phagocytophilum survival in LR-WB was not determined.

The storage temperature may have influenced RC survival and partially explains the findings of this study. In fact, the optimal culture and maintenance temperature for $\mathrm{RC}$ is $32{ }^{\circ} \mathrm{C}$ [25]; we assume that the blood storage temperature of $4{ }^{\circ} \mathrm{C}$ may have limited $\mathrm{RC}$ replication, maintaining $\mathrm{RC}$ viable but in a quiescent state, still able to infect cells in favourable culture conditions. Thus, the low temperature and the blood environment may favour 
the long-term survival of RC, even in absence of cells suitable to support bacterial replication.

This study had some limitations: (i) RC bacteria in the inoculum were not quantified precisely, but estimated based on the LOD of the PCR used, and this may have caused some variability among results of the five units; and (ii) the mechanical detachment of L929 infected cells for inoculum preparation may have induced the lysis of a portion of cells and the release of free $\mathrm{RC}$, reducing the ability of the filter to stop RC.

Apart the possible bias related to the experimental model, RC growth in LR-WB took longer than in WB, supporting the effect of leukoreduction to decrease the bacterial load. For the purpose of the study, the initial bacterial load was set on the LOD of the analytical method used (screening rPCR) and blood units were infected with a bacterial load at a level barely detectable by rPCR. This situation may simulate the field case of clinically healthy donor dogs, coming to donation with an ongoing subclinical infection and low bacterial load that could escape routine checks. $\mathrm{RC}$ circulating in the blood in an intracellular form (endothelial cells) or, to a minimum part free, can remain viable during the storage period and can potentially be transmitted to a recipient by blood transfusion. Little is known about the course of RC or Rickettsia spp. infection in dogs. Usually, RC infection is characterized by transient mild symptoms or subclinical presentation [6,7], which is confirmed by experimental infections $[4,5]$. Despite the high Rickettsia spp. seroprevalence reported in some regions [26, 27], clinical cases of RC in dogs are sporadic [6, 7], supporting the hypothesis of the low pathogenicity of RC for dogs. However, the transmission of RC to a critically-ill recipient with a compromised immune system would make this infection more severe.

For all these reasons, $\mathrm{RC}$ should be included in the screening panel of canine blood donors. However based on the results of this study, it is preferable to maintain a high standard of selection of healthy blood donors, in particular focusing on the prevention of tick-bites, rather than relying on the sensitivity of the laboratory methods used for screening.

\section{Conclusions}

$\mathrm{RC}$ infection can be a severe clinical threat in immunocompromised transfused dog patients. Leukoreduction reduced the bacterial load linked to the presence of $\mathrm{RC}$ in blood units, but the presence of free RC remains a possible risk for the recipient subjects. Leukoreduced blood units may remain potentially infectious for the entire blood bag shelf life, even due to small quantities of RC not easily detectable. An integrated approach that combines prevention of tick-bites with recurrent serological and molecular screening is recommendable for donor monitoring to reduce the risk of transfusion-transmitted tick-borne infections.

\section{Supplementary information}

Supplementary information accompanies this paper at https://doi. org/10.1186/s13071-020-3991-9.

Additional file 1: Table S1. Detailed results of the tests performed on blood units at different days post-infection (dpi) and on cultures from days 3 to 28. Rickettsia conorii was considered viable (v) or non-viable (nv), when the unit or the culture were positive/negative by RT-rPCR and/or immunofluorescence (IF).

\section{Abbreviations}

RC: Rickettsia conorii; WB: whole blood; LR-WB: leukoreduced whole blood; dpi: day post-infection; CPDA-1: citrate phosphate-dextrose-adenine; LOD: limit of detection; rPCR: real-time polymerase chain reaction; RT-rPCR: reverse transcriptase real-time polymerase chain reaction.

\section{Acknowledgements}

The paper has been sponsored by Bayer Animal Health in the framework of the 15th CVBD ${ }^{\circledR}$ World Forum Symposium. Cell-line and RC strain were kindly provided by the Centre National de Référence des Rickettsia, Coxiella, Bartonella, Marseille, France.

\section{Authors' contributions}

MV, LL, AN and AC designed the study. LL carried out L929 and RC culture, WB infection and $\mathrm{RC}$ isolation assessment from blood and drafted the manuscript. SR coordinated the molecular investigations and helped in drafting the manuscript. GDR and FT carried out molecular analyses. WW performed the blood units collection and managed leukoreduction procedures and blood units storage. MM helped in L929 cell line maintenance and RC isolation assessment. AC coordinated the blood units collection. PEF provided support in RC culture and isolation procedures and helped in drafting the manuscript. GC, AN and MV coordinated the study and participated in drafting the manuscript. All authors read and approved the final manuscript.

\section{Funding}

The study was financially supported by the Italian Ministry of Health (project code: RC IZSVE 04/15)

\section{Availability of data and materials}

Data supporting the conclusions of this article are included within the article and its additional file.

\section{Ethics approval and consent to participate}

The dogs' owners formally approved the use of part of the donation for research purposes before the sampling and they subscribed the information format. The signed forms are available from the author (MV).

\section{Consent for publication}

Not applicable.

\section{Competing interests}

The authors declare they have no competing interest.

\section{Author details}

${ }^{1}$ Istituto Zooprofilattico Sperimentale delle Venezie, Legnaro, PD, Italy. ${ }^{2}$ Centre National de Référence des Rickettsia, Coxiella, Bartonella, Marseille, France.

Received: 15 December 2019 Accepted: 24 February 2020

Published online: 21 April 2020 


\section{References}

1. Wardrop KJ, Birkenheuer A, Blais MC, Callan MB, Kohn B, Lappin MR, et al. Update on canine and feline blood donor screening for blood-borne pathogens. J Vet Intern Med. 2016;30:15-35.

2. Brouqui P, Parola P, Fournier PE, Raoult D. Spotted fever rickettsioses in southern and eastern Europe. FEMS Immunol Med Microbiol. 2007;49:2-12

3. Parola P, Socolovschi C, Raoult D. Deciphering the relationships between Rickettsia conorii conorii and Rhipicephalus sanguineus in the ecology and epidemiology of Mediterranean spotted fever. Ann N Y Acad Sci. 2009;1166:49-54

4. Levin ML, Killmaster LF, Zemtsova GE. Domestic dogs (Canis familiaris) as reservoir hosts for Rickettsia conorii. Vector Borne Zoonotic Dis. 2012:12:28-33

5. Kelly PJ, Matthewman LA, Mason PR, Courtney S, Katsande C, Rukwava J. Experimental infection of dogs with a Zimbabwean strain of Rickettsia conorii. J Trop Med Hyg. 1992;95:322-6.

6. Solano-Gallego L, Kidd L, Trotta M, Di Marco M, Caldin M, Furlanello T, et al. Febrile illness associated with Rickettsia conorii infection in dogs from Sicily. Emerg Infect Dis. 2006:12:1985-8.

7. Solano-Gallego L, Caprì A, Pennisi MG, Caldin M, Furlanello T, Trotta M. Acute febrile illness is associated with Rickettsia spp. infection in dogs. Parasit Vectors. 2015;8:216.

8. Leiby DA, Gill JE. Transfusion-transmitted tick-borne infections: a cornucopia of threats. Transfus Med Rev. 2004;18:293-306.

9. Kalantarpour F, Chowdhury I, Wormser GP, Aguero-Rosenfeld ME. Survival of the human granulocytic ehrlichiosis agent under refrigeration conditions. J Clin Microbiol. 2000;38:2398-9.

10. Eberhard ML, Walker EM, Steurer FJ. Survival and infectivity of Babesia in blood maintained at $25^{\circ} \mathrm{C}$ and $2-4{ }^{\circ} \mathrm{C}$. J Parasitol. 1995;81:790-2.

11. Mintz ED, Anderson JF, Cable RG, Hadler JL. Transfusion-transmitted babesiosis: a case report from a new endemic area. Transfusion. 1991;31:365-8.

12. Wells GM, Woodward TE, Fiset P, Hornick RB. Rocky mountain spotted fever caused by blood transfusion. JAMA. 1978;239:2763-5.

13. Brownlee L, Wardrop KJ, Sellon RK, Meyers KM. Use of a prestorage leukoreduction filter effectively removes leukocytes from canine whole blood while preserving red blood cell viability. J Vet Intern Med. 2000;14:412-7.

14. Mettille FC, Salata KF, Belanger KJ, Casleton BG, Kelly DJ. Reducing the risk of transfusion-transmitted rickettsial disease by WBC filtration, using Orientia tsutsugamushi in a model system. Transfusion. 2000;40:290-6.
15. Proctor MC, Leiby DA. Do leukoreduction filters passively reduce the transmission risk of human granulocytic anaplasmosis? Transfusion. 2015:55:1242-8.

16. Linea guida relativa all'esercizio delle attività sanitarie riguardanti la medicina trasfusionale in campo veterinario. In: Gazzetta Ufficiale Serie Generale n.25, 01/02/2016, pag 6. https://www.gazzettaufficiale.it/eli/ gu/2016/02/01/25/sg/pdf. Accessed 21 Feb 2020

17. Balraj P, Vestris G, Raoult D, Renesto P. Comparison of Rickettsia conorii growth within different cell lines by real-time quantitative PCR. Clin Microbiol Infect. 2009;15(Suppl. 2):294-5.

18. Lagier J, Edouard S, Pagnier I, Mediannikov O, Drancourt M, Raoult D. Current and past strategies for bacterial culture in clinical microbiology. Clin Microbiol Rev. 2015;28:208-36.

19. Choi Y, Jang W, Kim J, Ryu J, Lee S, Park K, et al. Spotted fever group and typhus group rickettsioses in humans, South Korea. Emerg Infect Dis. 2005:11:237-44.

20. Botelho-Nevers E, Edouard S, Leroy Q, Raoult D. Deleterious effect of ciprofloxacin on Rickettsia conorii-infected cells is linked to toxin-antitoxin module up-regulation. J Antimicrob Chemother. 2012;67:1677-82.

21. Marrero M, Raoult D. Centrifugation-shell vial technique for rapid detection of Mediterranean spotted fever Rickettsia in blood bulture. Am J Trop Med Hyg. 1989;40:197-9.

22. Landis JR, Koch GG. The measurement of observer agreement for categorical data. Biometrics. 1977;33:159-74.

23. Kersh GJ, Priestley R, Massung RF. Stability of Coxiella burnetii in stored human blood. Transfusion. 2013;53:1493-6.

24. Coleman SA, Fischer ER, Howe D, Mead DJ, Heinzen RA. Temporal analysis of Coxiella burnetii morphological differentiation. J Bacteriol. 2004;186:7344-52.

25. Edouard S, Raoult D. Use of the plaque assay for testing the antibiotic susceptibility of intracellular bacteria. Future Microbiol. 2013:8:1301-6.

26. Solano-Gallego L, Trotta M, Caldin M, Furlanello T. Molecular survey of Rickettsia spp. in sick dogs in Italy. Zoonoses Public Health. 2008;55:521-5.

27. Vascellari M, Ravagnan S, Carminato A, Cazzin S, Carli E, Da Rold G, et al. Exposure to vector-borne pathogens in candidate blood donor and freeroaming dogs of northeast Italy. Parasit Vectors. 2016;9:369.

\section{Publisher's Note}

Springer Nature remains neutral with regard to jurisdictional claims in published maps and institutional affiliations.
Ready to submit your research? Choose BMC and benefit from:

- fast, convenient online submission

- thorough peer review by experienced researchers in your field

- rapid publication on acceptance

- support for research data, including large and complex data types

- gold Open Access which fosters wider collaboration and increased citations

- maximum visibility for your research: over 100M website views per year

At BMC, research is always in progress.

Learn more biomedcentral.com/submissions 